\title{
Autologous fascia lata for heart valve replacement
}

\author{
MARIAN I. IONESCU, DONALD N. ROSS, RADU DEAC, \\ VER N ON A. GRIMSHAW, STANLEY H. TA Y L OR, \\ W. WH IT AKER, GEOFFREY H. W O OLER \\ Department of Cardio-thoracic Surgery, The General Infirmary at Leeds, Leeds University, \\ the National Heart Hospital, and Guy's Hospital, London
}

\begin{abstract}
To obviate the drawbacks of prosthetic devices and in search of a better substitute for diseased heart valves a technique of using autologous fascia lata grafts attached to a support frame was developed. The technique of preparing mounted fascia lata grafts is briefly outlined and their surgical implantation into the mitral, tricuspid, and aortic areas is described. Since April 1969, 83 fascial grafts have been inserted into 76 patients with very good immediate and short-term results. Ten patients succumbed within the operative period. None of these deaths was due to failure of the graft per se. Thromboembolic manifestations have been completely absent although anticoagulants were not used. All sixty-six survivors are very much improved. Data concerning the structure and function of fascia are presented and the experimental and clinical use of fascia lata in extracardiac and cardiac surgery is reviewed. The use of autologous, living, fascia lata valves is considered to be a better approach for heart valve replacement because autologous fascia maintains its structure unchanged after transplantation and, being under mechanical stimulation, it retains its functional properties.
\end{abstract}

Replacement of diseased heart valves remains a challenge for the cardiac surgeon. There is no ideal substitute yet available for valve replacement, mainly because of the remarkable properties and capabilities of living valve tissue.

Clinical experience with prosthetic valves has shown satisfactory results over a period of six to eight years, but their use is still associated with complications and accidents that are difficult to avoid. Among the complications connected with prosthetic valve replacement thromboembolism, impaired haemodynamic function, destruction of red cells, mechanical failure, haemorrhage, and infection are the most important.

To obviate the drawbacks of prosthetic valves, free homografts (Ross, 1962, 1967a ; BarrattBoyes, 1964) and heterografts (Binet, Duran, Carpentier, and Langlois, 1965 ; O’Brien, 1967) have been used with success for replacement of the aortic valve.

For mitral and tricuspid replacement, heterologous aortic valves (Ionescu, Wooler, Smith, and Grimshaw, 1967 ; Ionescu, Wooler, Whitaker, Smith, Taylor, and Hargreaves, 1968 ; Carpentier, Blondeau, Laurens, Mancel, Laurent, and Dubost, 1968) and homologous aortic valves (Angell, Stinson, Iben, and Shumway, 1968) attached to a supporting frame have been used successfully over the past three years.
There are many advantages of homo- and heterografts compared with mechanical prostheses, the two main ones being the absence of thromboembolism and a near normal haemodynamic result.

In the majority of cases the grafts used are non-viable, sterilized, preserved tissues. Their longterm fate is uncertain despite the fact that some are functioning satisfactorily up to seven years post-operatively.

There is particular concern about late calcification, fibrous thickening of the cusps, and late disintegration of the cusp tissue (Duran, Manley, and Gunning, 1965; Hudson, 1966; Ross, 1967a ; Smith, 1967 ; Brock, 1968).

Almost all non-viable homograft valves re- 을 moved from patients after implantation in the $N$ aortic root had acellular cusps (Hudson, 1966; Smith, 1967; Ross, personal data), while the 0 majority of non-viable heterografts were seen to $\mathrm{\omega}$ contain cells six to eight months after implanta- 0 tion in the mitral annulus (Sutherland and Ionescu, $\infty$ personal data).

This difference in the reaction of the host is not $\stackrel{?}{+}$ understood. It may be due to the fact that the 7 mitral annulus is more vascular than the aortic. Also it is not known whether the cellular infiltra- $\stackrel{\mathbb{\Omega}}{\Omega}$ tion seen in heterologous grafts is beneficial or $\mathbb{Q}$ not to the graft. 
Lower, Pillsbury, Angell, and Kosek (1966) consider that freeze-dried or sterilized tissues do not provide an effective latticework for host replacement, and the findings in other published reports support this opinion.

It appears likely that there is a difference in host reaction to fresh and treated material, presumably due to denature of some of the proteins from the graft by freeze-drying and reconstitution and also to alteration of the electrical potential in the dead graft.

These theoretical speculations together with clinical and pathological findings support the statement that 'there is not a single instance where an autograft is not superior to a homograft as grafting material' (Peer, 1955).

In an attempt to improve long-term fate, Ross (1967b) used viable autologous pulmonary valve grafts in the aortic position and replaced the excised pulmonary valve with a homologous aortic valve. In this position the preserved homograft is not subjected to systemic pressure and is likely to have a better long-term prognosis. This procedure, successful in the authors' hands, seems too complicated to become routine in every surgical centre.

Senning (1967) used autologous fascia lata for repair and replacement of the aortic valve with very good results over a period of six years. His technique applies to the aortic valve only, but it demonstrates that autologous fascia remains viable and well preserved years after implantation as valve replacement.

Stimulated by Senning's results we developed a technique of heart valve replacement with autologous fascia lata attached to a supporting frame to be used in the mitral, tricuspid, and aortic positions (Ionescu and Ross, 1969 ; Ionescu, Ross, Holden, Hargreaves, and Wooler, 1970).

This paper both outlines the techniques of preparation and surgical implantation of the fascia lata graft into these three positions and presents our early results with 76 patients operated upon since April 1969 at the General Infirmary at Leeds and the National Heart Hospital and Guy's Hospital, London.

\section{PREPARATION OF FASCIA LATA GRAFTS}

The method employed in making the valve is basically the same for all three positions. The supporting frame consists of a thin-walled titanium stent with a scallopshaped ring and three narrow prongs, each with two perforations close to the free end for suture attachment of the fascia commissures. This titanium frame is entirely covered both inside and outside with
Dacron velour. ${ }^{1}$ The large suturing skirt is reinforced inside with a Dacron felt $^{2}$ rim (Fig. 1).

Sizes from 26 to $32 \mathrm{~mm}$. internal diameter are available for the mitral and tricuspid positions; the sizes for subcoronary insertion vary from 16 to 26 $\mathrm{mm}$. inside diameter. For paediatric use frames with an inside diameter of 22 and $24 \mathrm{~mm}$. are available. ${ }^{2}$

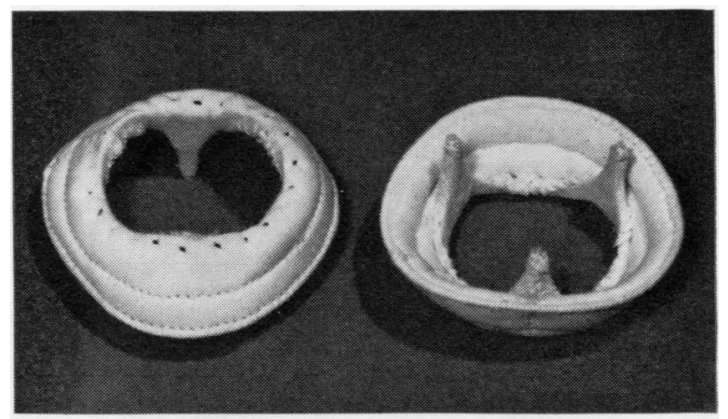

FIG. 1. Supporting frame for fascia lata valve grafts. The titanium structure is covered with Dacron velour and provided with a large suturing rim.

Immediately after the patient has been anaesthetized a strip of fascia lata is removed from the lateral aspect of the thigh. This should be a little larger than is considered necessary in order to choose a part without vascular perforations (Table I).

T A B L E I

SIZES FOR FASCIA LATA VALVE GRAFTS

\begin{tabular}{c|cc|c|c}
\hline $\begin{array}{c}\text { Internal } \\
\text { Diameter } \\
\begin{array}{c}\text { Dacron- } \\
\text { covered } \\
\text { Frame } \\
\text { (mm.) }\end{array}\end{array}$ & $\begin{array}{c}\text { Length } \\
\text { (mm.) }\end{array}$ & $\begin{array}{c}\text { Width } \\
\text { (mm.) }\end{array}$ & $\begin{array}{c}\text { Functional } \\
\text { Opening of } \\
\text { Valve Graft } \\
\text { (mm.) }\end{array}$ & $\begin{array}{c}\text { Diameter of } \\
\text { Heart Valve } \\
\text { to Accept } \\
\text { Graft } \\
\text { (mm.) }\end{array}$ \\
\cline { 2 - 4 } 16 & 72 & 15 & 13 & 22 \\
18 & 78 & 16 & 15 & 24 \\
20 & 84 & 18 & 17 & 26 \\
22 & 91 & 21 & 19 & 28 \\
24 & 97 & 22 & 21 & 30 \\
26 & 104 & 23 & 23 & 32 \\
28 & 111 & 24 & 25 & 34 \\
30 & 117 & 25 & 27 & 36 \\
32 & 123 & 27 & 29 & 38 \\
\hline
\end{tabular}

Both surfaces of the fascia are trimmed, and fat and loose connective tissue is removed. In order to obtain a suitable rectangular piece, the fascia is measured and cut in such a way as to have one margin parallel to the direction of the longitudinal fibres. The two ends of the fascia strip are sutured together along two-thirds of their width using a double continuous 4-0 stitch. This will make the fascial strip into a cylinder. The edge which has been cut along the

1 U.S. Catheter and Instrument Corp., Glen Falls, N.Y. ${ }^{2}$ Commercially available from Hypodermic Services, 45 Hare Park Lane, Hightown, Liversedge, Yorkshire, Great Britain 
longitudinal fibres is placed uppermost to become the free margin of the cusps. This edge is marked with three 5-0 stitches at equidistant points using a Teflon cone as a guide (Fig. 2). The fascia lata cylinder is

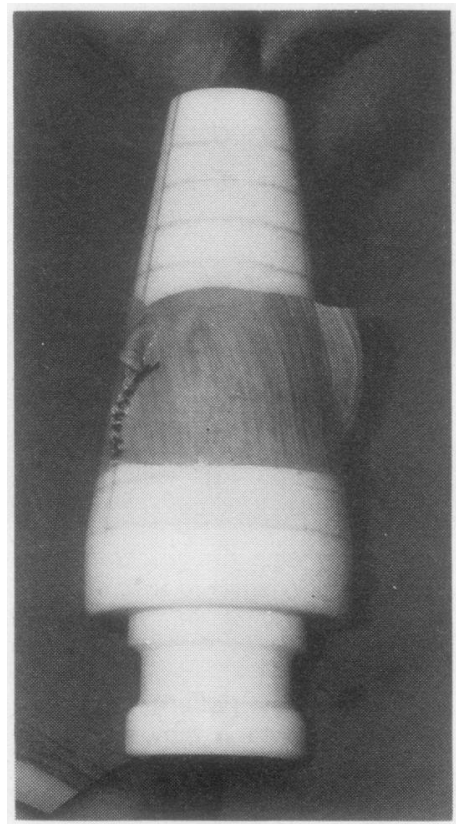

FIG. 2. The fascial cylinder is placed over the Teflon cone and marked at three equidistant points with fine sutures.

then placed over the supporting frame outside the prongs and the three commissural points are attached to the top of the prongs with 4-0 stitches passed through the perforations of the frame and tied outside over a piece of knitted Teflon (Fig. 3).

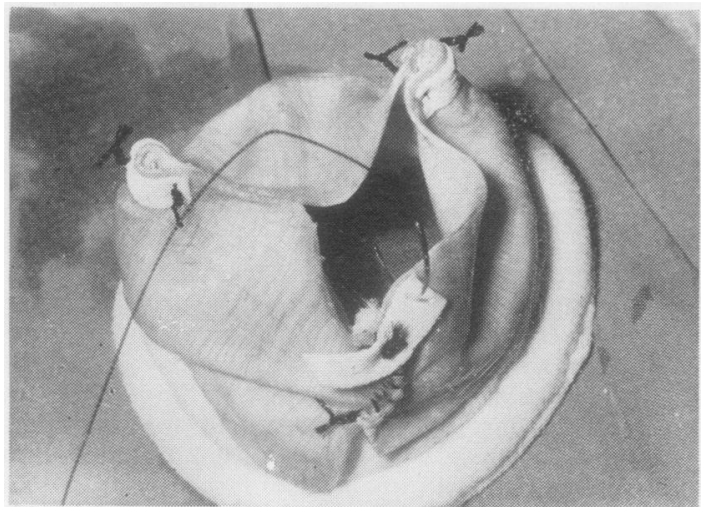

FIG. 3. The fascia lata cylinder was placed over the supporting frame and the three commissural points were attached to the top of the prongs. The sutures are passed through and tied over Teflon knit patches.
After attaching the commissural points to the frame, $\stackrel{\overline{\bar{N}}}{\stackrel{+}{+}}$ the fascial tissue is moulded in such a way as to produce three equal cusps. While maintaining with a믐 finger the position of each newly created cusp, the lower end of the fascia is stitched with a continuous $\mathbb{D}$ 4-0 Mersilene suture to the scallop-shaped margin of the frame (Fig. 4). The redundant tissue at this loweres margin is removed and the valve is ready for implanta- $\overrightarrow{0}$ tion (Fig. 5).

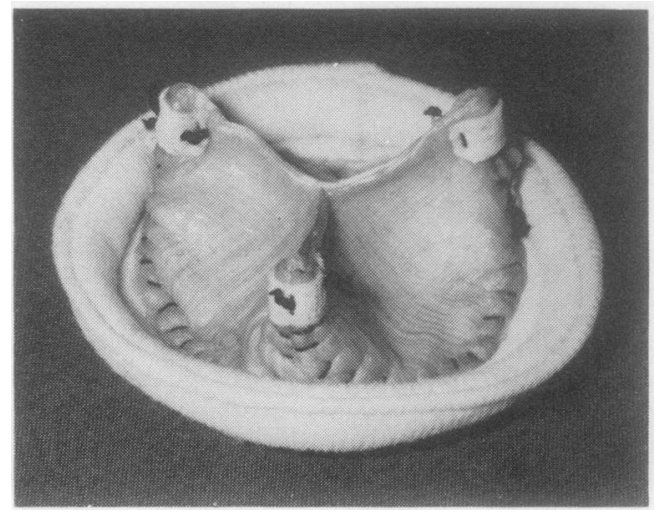

FIG. 4. The lower end of the fascia lata cylinder was sutured to the Dacron cloth covering the scallop-shaped $\frac{\mathrm{Q}}{\mathrm{Q}}$ margin of the support frame.

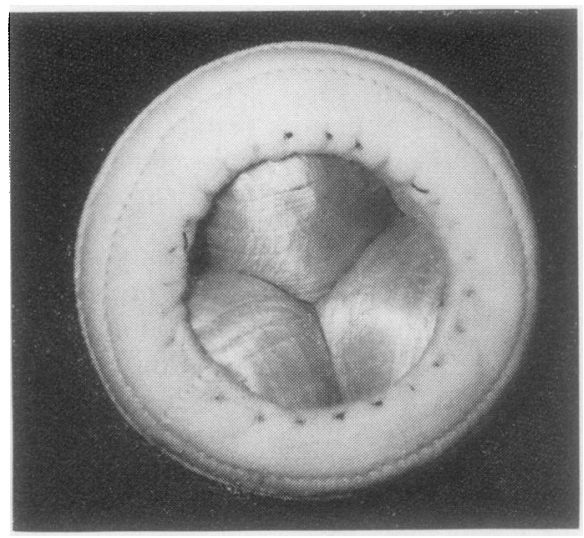

FIG. 5. Fascia lata valve graft seen from the convex aspect with the cusps in the closed position.

To simplify the construction of fascial grafts a plastic mould has been designed. The valve, after $\overline{0}$ attachment to the prongs of the frame, is fixed in $\overrightarrow{\mathbb{D}}$ between the male and female components of the $\frac{\rho}{\mathbb{D}}$ mould. The complete assembly is then secured in a spring-loaded clamp and the lower end of the fascialo 


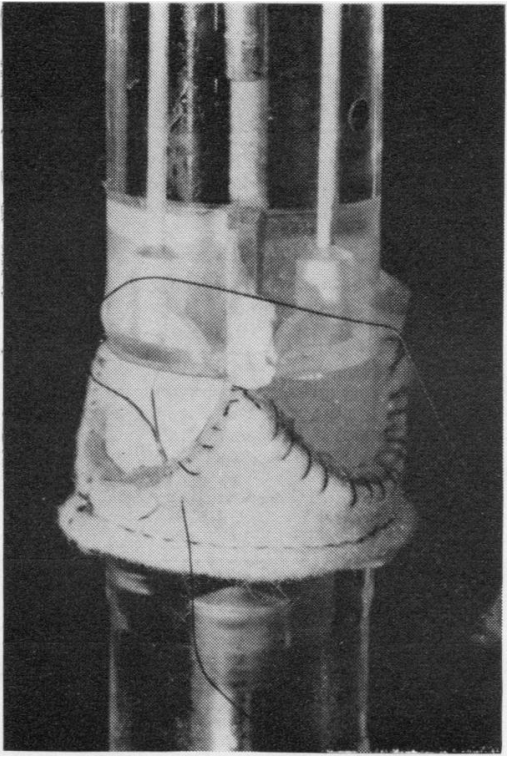

FIG. 6. The assembly mould fixed in a spring-loaded clamp holding together the fascia lata graft and the frame support for suturing.

cylinder is sutured to the Dacron-covered frame (Fig. 6) (Ionescu, Ross, Wooler, Deac, and Ray, 1970).

\section{SURGICAL IMPLANTATION}

For all valve replacements a single layer of interrupted stitches is used. In the mitral position the graft is orientated in such a way as to place two prongs supporting a cusp on each side of the aortic root. After the sutures have been tied, the graft is positioned halfway between the ventricle and the atrium (Fig. 7).

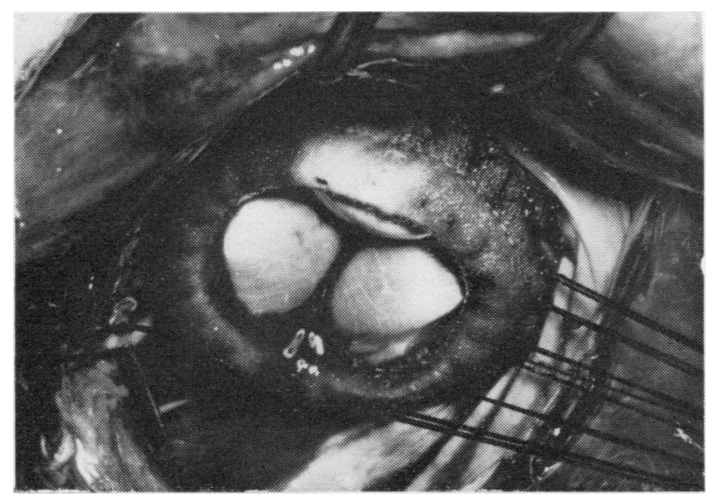

FIG. 7. Supported autologous fascia lata valve graft sutured to the mitral annulus. The valve is positioned midway between the ventricle and the atrium.
For tricuspid valve replacement there are no special points to be made ; the fascia graft is inserted in the same way as a prosthesis either above or at the level of the tricuspid annulus, depending on the surgeon's choice.

In the subcoronary position, the frame-supported fascia graft is sutured as easily and as rapidly as a Starr prosthesis. We favour anoxic arrest of the heart at euthermic level because the whole intracardiac procedure usually takes less than 45 minutes (Fig. 8).

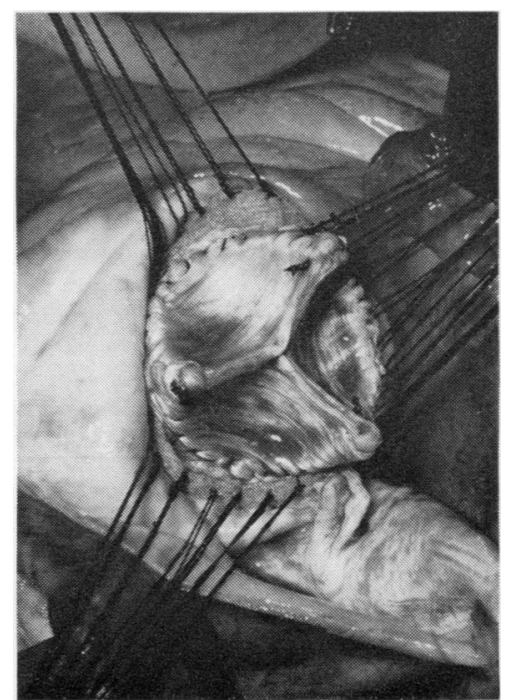

FIG. 8. Supported autologous fascia lata valve graft sutured to the aortic annulus. The glistening surface of the fascia is orientated towards the aorta.

\section{CLINICAL MATERIAL}

This clinical series consists of 76 patients operated upon since April 1969. All had one or two heart valves replaced with autologous fascia lata grafts attached to a support frame. There were 29 males and 47 females. Their ages ranged from 9 to 73 years.

In Table II are listed the types of heart disease, the number of patients in each category, and the type of operation performed.

In Table III are listed the associated abnormalities. The majority of patients operated upon had full haemodynamic studies with exercise tests performed preoperatively. Approximately $60 \%$ of the patients investigated had a cardiac output of between 1.5 and $1.91 . / \mathrm{sq} . \mathrm{m} . /$ minute, a stroke volume of between 15 and $35 \mathrm{ml}$., and a poor response to exercise with a fixed stroke volume and considerably raised left atrial and pulmonary artery pressures. All mitral and double valve replacement patients have received hydrocorti- 
sone $(30 \mathrm{mg}$. $/ \mathrm{kg}$. body weight) immediately before the start of the heart-lung bypass, and 40 units of soluble insulin during and after the perfusion. When the mitral valve was replaced a moderate degree of aortic regurgitation (grade $1 / 6$ and $2 / 6$ ) or a moderate degree of functional tricuspid regurgitation was left uncorrected.

RESULTS As seen from Table IV there have been 10 deaths within the operative period. Four patients died in acute cardiac failure two hours to seven days postoperatively; two developed arrhythmias-probably due to digitalis overdose; and the remaining four succumbed due to haemorrhage, infection, and cerebral damage.

None of these deaths was due to failure of the graft per se. In one patient, mitral incompetence was probably produced at the time of operation. One suture looped around one of the prongs supporting a commissure and was tied in that position. Although this graft was competent under pressure when tested in a pulse-duplicator with the misplaced suture around

\section{T A B LE I I}

HEART VALVE REPLACEMENT WITH AUTOLOGOUS FASCIA LATA GRAFTS (76 PATIENTS)

(a) Mitral valve replacement (from 9 to 62 years old) (13 males and 34 females)

\begin{tabular}{lrr}
\hline Mixed mitral valve lesion & 37 \\
With heailvy calcification & 21 & \\
In children 9 to 12 years old & 2 & \\
With aneurysmal left atrium & 5 & \\
With associated tricuspid regurgitation & 3 & 5 \\
Mitral regurgitation & 1 & 5 \\
Ruptured chordae tendineae & 2 & 5 \\
Calcified mitral stenosis & \\
\hline With associated tricuspid regurgitation* & 2 & \\
\hline
\end{tabular}

*Tricuspid annnuloplasty was performed

(b) Aortic valve replacement (from 21 to 56 years old)

(13 males and 3 females)

Aortic stenosis

Heavily calcified

With aneurysmal dilatation of sinuses of Valsalva

With associated mitral stenosis*

Aortic regurgitation

With aneurysmal dila tation of the

ascending aorta

With aneurysmal dilatation of sinuses

of Valsalva

With associated coarctation of the aorta

*Mitral valvotomy was performed

(c) Tricuspid valve replacement (64 years and 73 years old)

(1 male and 1 female)

Rheumatic tricuspid valve disease

With associated mitral stenosis*

With associated trivial aortic regurgitation

* Mitral valvotomy was performed

(d) Multiple valve replacement (from 35 to 55 years old) ( 2 males and 9 females)

Mitral and aortic valve disease*

Mitral and tricuspid valve disease

$\begin{array}{ll} & 11 \\ 3 & \end{array}$

*Three patients had the aortic valve replaced with an aortic homograft, and one patient with a free, unmounted fascia lata graft. In the remaining four patients a frame-mounted fascia lata graft was used for aortic replacement.
T A B L E I I I

ASSOCIATED ABNORMALITIES IN 76 PATIENTS UNDERE GOING HEART VALVE REPLACEMENT WITH AUTOO LOGOUS FASCIA LATA

Mitral valve replacement

Previous (one or two) closed mitral valvotomies

Aortic regurgitation

$$
\begin{array}{ll}
\text { Grade 1/6 } & 9 \\
\text { Grade 2/6 } & 5 \\
\text { Grade 3/6 } & 1
\end{array}
$$

Tricuspid regurgitation

$50 \%$ of systemic Severely impaired renal, hepatic or respiratory function

Aortic valve replacement

Previous aortic homograft valve replacement

Previous aortic homograft valve replacement

Previous Starr prosthesis (infected)

Aneurysmal dilatation of sinuses of Valsalva

Mitral stenosis

Aneurysmal dilatation of the ascending aorta

Coarctation of the aorta

Pulmonary hypertension

Tricuspid valve replacement

Mitral stenosis

Aortic regurgitation (grade 2/6)

Multiple valve replacement

Pulmonary hypertension above $50 \%$ of systemic

Previous mitral valvotomy

Severely impaired renal, hepatic or respiratory function 3

3 .
OPERATIVE MORTALITY (10 DEATHS WITHIN ONE M ONTIি

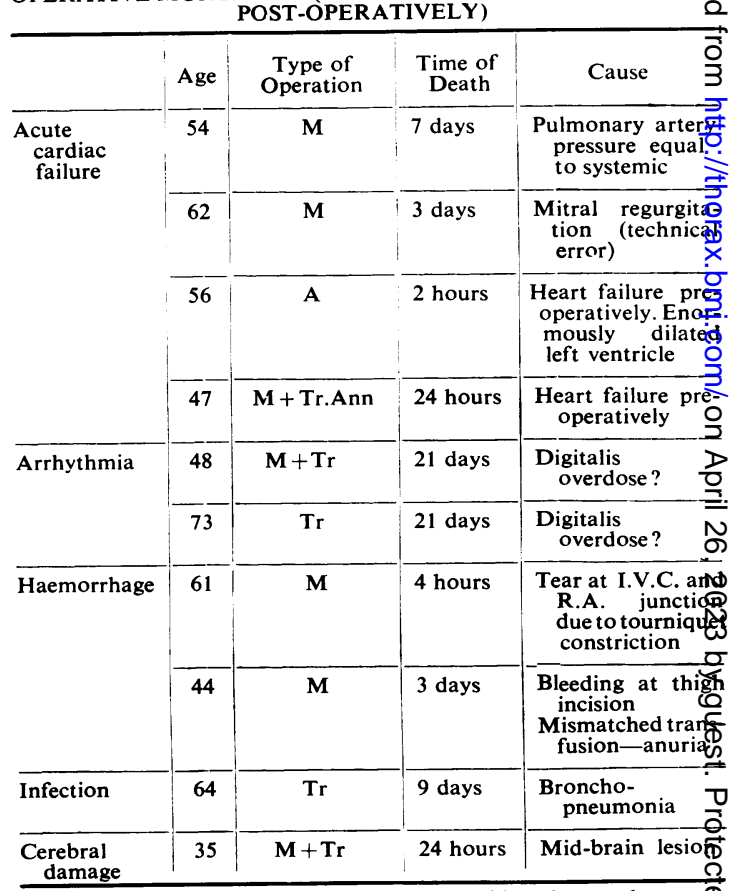

$M=$ mitral valve replacement; $\mathrm{Tr}=$ tricuspid valve replacement; I.V.C. = inferior vena cava; $A=$ aortic valve replacement; Tr.A $n$ n. tricuspid annuloplasty; R.A. = right atrium. 


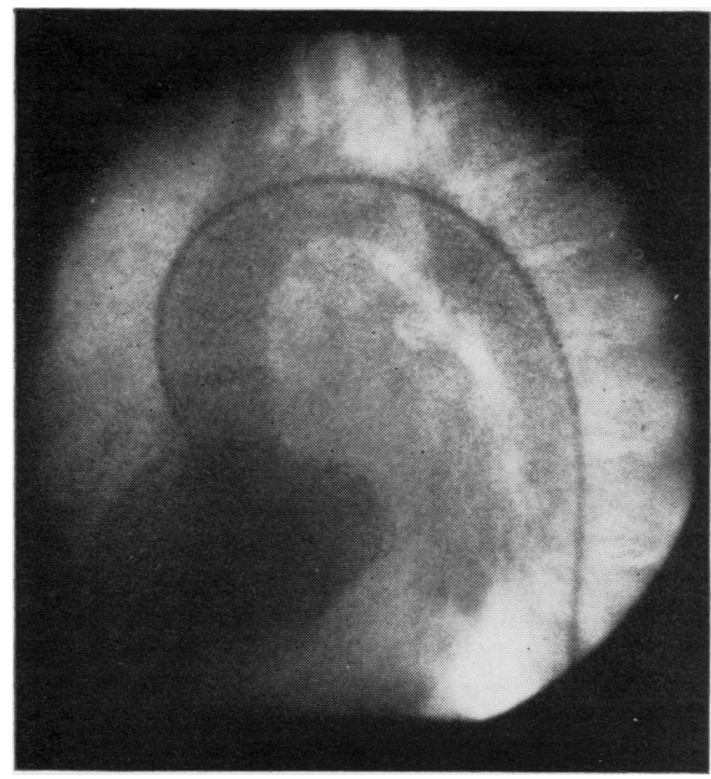

FIG. 9. One frame from a ciné-angiogram performed with contrast medium injected into the left ventricular cavity. The fascia lata valve graft is in the closed position. There is no regurgitation into the atrium.

the prong, we consider that it might have contributed to the development of heart failure.

From the total of 76 patients operated upon, 66 are alive and very much improved (Fig. 9). All patients with mitral or tricuspid valve replacement have normal heart sounds. Patients with aortic replacement gave a grade 1 aortic systolic murmur. The postoperative evolution of these patients was remarkably smooth and uneventful despite their critical preoperative condition and the high incidence of associated abnormalities. Thromboembolic manifestations have been completely absent although anticoagulants were not used.

\section{DISCUSSION}

STRUCTURE AND FUNCTION OF FASCIA Fascia is composed of a large volume of matrix and a few cells. The matrix is represented by dense bundles of collagenous fibres and a few elastic fibres. Fibroblasts, which are the parenchymal cells of fascia, are scattered rather sparsely between the collagenous fibres.

Collagenous fibres, which possess great tensile strength, appear to have longitudinal striations due to the fact that each fibre is composed of numerous fibrils running in a longitudinal direction. Electron microscopic examination has shown that the individual fibrils have a cross-striated appearance, suggesting that they are composed of alternating bands of material.

Concerning the process of collagenous fibre formation, Stearns (1940) showed that fibroblasts throw off small masses of cytoplasmic material which, after they are completely free of the cells, give rise to the formation of collagenous fibres.

Tension appears to be a mechanical factor in stimulating their production and also in determining their direction or orientation. The life span of collagenous fibres is not known, but certainly they can be replaced abundantly when there is a loss of tissue or a need for their presence, as in wound healing.

Elastic fibres, which are much less numerous than collagenous fibres, appear as rather delicate homogeneous threads, frequently branching to form a sort of loose network. Elastic fibres do not seem to be composed of fibrils as are collagenous fibres. According to Le Gros Clark (1952) and Cowdry (1950), the developmental origin of elastic fibres is still obscure. They appear to be made from the alignment of refractile granules laid down in the intercellular matrix by some unknown agency. The probability is that they are not formed by the fibroblast.

There is no evidence that new elastic fibres can be produced when they have been destroyed, and it seems possible that the original fibres last through the individual's lifetime.

Elastic fibres may survive free transplantation and may remain during the life-span of the human recipient (Peer, 1955).

The parenchymal cell of fascia, which is the fibroblast, is the only essential cell type present in this tissue. It arises from mesenchymal cells and quantities of collagen soon appear around them. This collagen differentiates into collagenous fibres which form different types of dense fascia according to forces of stress and strain.

It is possible that the ordinary parenchymal connective tissue cells in fascia can take part in a new matrix formation as well as form collagenous fibres in wound healing.

The amorphous part of the intercellular material consists of the usual hyaluronic acid and cement substances which surround the collagenous and elastic fibres and the cells. The whole tissue is bathed and surrounded by tissue fluid, so substances pass from capillaries to cells and vice versa through this aqueous medium.

Since deep fascia is composed largely of intercellular substance rather than cells, the tissue requires little blood supply. It is therefore only 
sparsely supplied with blood vessels, and it is a relatively non-vascular tissue. It contains both nerve elements and lymphatics.

Hartig (1966) studied the functional structure of fascia and reached interesting conclusions as far as adaptability to forces of tension and stress are concerned. He pointed out that fascia is to be seen as a three-dimensional structure and not as a surface. The great power of adaptation of fascia does not depend only on its scissor-like or $x$-like network, since changes in this system are restricted to two dimensions only. There are fibres which cross the fascia forming a third dimension to the network. In this way, when it changes its shape the volume remains constant.

EXPERIMIENTAL AND CLINICAL USE OF FASCIA Transplantation of fascia was initiated by McArthur (1901, 1904), who used strips of aponeurosis as suture material in the repair of herniae, and Murphy (1904), who used pedicle transplants of fascia in arthroplasty.

Kirschner (1909) reported the successful use of autogenous fascia grafts in animals and stated that the transplants retained their structure after transfer and remained in the host area as living tissue. This report stimulated a great interest for further experimental and clinical work.

Kirschner (1910) was probably the first to transplant fascia in humans and later expose the grafts and observe that grossly the transplants had not been absorbed and that they appearzd exactly like fascia.

McArthur (1913) showed microscopically that 'cells supplied with sufficient appropriate plasma, under conditions approximating those of life, will live and multiply, each retaining its own particular characteristic'. He made a statement which is more accurate than many later statements by others on the behaviour of free autografts, namely, that 'under aseptic conditions almost any autogenous graft may remain viable in any other part of the donor's anatomy'.

Shaw (1915) held that for the first few days a transplant must obtain its chief nourishment from lymph exudate supplied by the surrounding tissues, and eventually from vascular connections. Therefore the less vascular the transplant is and the more vascular the soil, the greater is the assurance of success.

In 1916 Wierzejewski noted that without mechanical demand fascia maintains its structure but it shrinks about one-fifth to one-sixth in volume.
Lewis (1917) considered fascia an ideal materia for transplantation; being thin, it is easily pero meated by serum and it undergoes little or nE degenerative change after direct transplantation. $\overrightarrow{\widetilde{D}}$

Neuhof (1923) maintained that in not a single instance had transplanted fascia been extruded? not even in patients in whom infection had beeB present or had appeared post-operatively.

In careful experimental work with rabbit Gallie and LeMesurier (1921) demonstrated that the fibroblast cells in autogenous fascia grafts rex mained viable after transplantation and that the graft retained its usual structure.

Gallie (1948) and Gallie and LeMesurier (192 安) 1922, 1924), after extensive experimental studie and successful clinical work, expressed the belief that fascia lata may be transplanted from orf place in the body to another and continue to live as demonstrated by histological studies an: clinical experience. They stated that the cells and fibres continue to stain well, thus showing ne necrosis. There is no evidence of invasion capillaries or infiltration with leucocytes. In spect mens recovered years after transplantation the was no indication of any great change in the tiss or of marked disturbance in its physiologic value.

In later work, Gallie and LeMesurier (194\% and Gallie (1948) made microscopic examination of autogenous fascia grafts buried in humans for six and 10 years respectively, and noted that grossly and histologically the graft structure ref sembled that of normal fascia.

Bunnell (1928) agreed with Gallie and L Mesurier in the belief that autogenous fascia grafs remained viable following successful transplant tion.

Foshee $(1943,1947)$, in studies concerning the removal of fascia lata in about 300 individua 8 , observed a bulge of the thigh muscles for a fer months, which disappeared after six months $\underline{\text { In }}$ every patient who had been followed up.

Fascia lata regenerates to fill a defect in a donor area where fascia has been removed.

Chandy (1946) used pieces of ox fascia pre served in $70 \%$ alcohol and studied them over period of four years. His conclusions were thet preserved tissue does not in itself become a livifg tissue at any time. When tissue is dead, its intracellular chemistry undergoes changes and the dovitalized material is absorbed and replaced other tissue cells. The absorption may be slow off the material has been fixed in alcohol. The amount of foreign body reaction depends upon 
chemical and physical nature of the foreign body. The fixed connective tissue cells, not being irritating, do not necessarily have to produce such a reaction. There is, however, sufficient phagocytosis for the absorption of the foreign cellular detritus.

Peer (1955) buried autogenous fascia lata grafts in human abdominal fat and removed the grafts at different intervals from 24 hours to $1 \frac{1}{2}$ years. At four months and 18 months the fascia grafts had an entirely normal appearance, except that there were about twice as many fibroblasts present as are seen in normal control fascia. The appearance and arrangement of the collagenous fibres were identical with those of normal fascia. Mass infiltration by host fibroblasts into the structure of the graft was not evident.

The same author's experimental work with preserved homologous fascia grafts in humans indicates considerable reaction to the graft, possibly on an antigen-antibody basis. The host's blood vessels and fibroblasts grew into the graft structure, and the fibroblasts and blood vessels of the graft disappeared. Large cellular infiltrations of the inflammatory type were present within and outside the graft up to eight months after transplantation.

Pullinger and Pirie (1942) implanted strips of fascia lata beneath the facial skin as autologous grafts. When removed one year later no cellular activity was noted around them; they retained their original structure even microscopically.

The influence of functional activity on the healing of tendon has been widely studied since 1891 , when Viering showed that functional stimulation influenced the orientation of cells in healing tendon. He showed further, and Schwarz (1922) confirmed, that non-specialized connective tissue transplanted into a tendon defect gradually assumed a tendon-like structure if it were subjected to a functional stimulus.

The analogy between tendon and fascia gives even more support to the theory of fascia behaviour after autotransplantation because tendon is a somewhat more complicated tissue containing two types of parenchymal cells.

On theoretical grounds, another interesting parallelism could be presented to support the idea that a simple structure, possessing a unique type of parenchymal cell scattered in a large mass of fibres and ground substance, survives after autotransplantation and retains its structural and functional properties indefinitely (Gibson, 1968).

The chondrocyte is the only parenchymal cell of cartilage. It is a versatile cell which alone is responsible for the elaboration of the matrix which surrounds it. It is also a very active cell, continuously 'servicing' the matrix. In addition, cartilage transplanted homogeneically survives if the chondrocytes survive transplantation (Leopold, 1881). This phenomenon of not provoking an immune response seems to be unique.

Gibson, Davis, and Curran (1958), in a series of experimental cartilage homografts in man, found the chondrocytes actively metabolizing sulphur throughout the two-year period of the experiment.

Later Gibson and Davis (1960) demonstrated living chondrocytes in a graft of a mother's ear cartilage transplanted to her child 18 years previously.

That these living cells are the original chondrocytes and not host cells repopulating the matrix is apparent from two facts-first, chondrocyte repopulation of dead cartilage is never observed; secondly, Peer (1958) showed that the sex chromatin structure of the surviving cells is that of the donor.

Concerning heart valve replacement, fascia lata has been used only during the last few years.

Flege, Rossi, Auer, and Ehrenhaft (1967) inserted a bicuspid valve with chordae tendineae in the mitral position in dogs, with discouraging results.

Gilbert, Mansour, Sanders, and Gravanis (1968) used patches and leaflet type grafts in the tricuspid position in dogs. Their results, too, were discouraging. The fascia lata grafts underwent degeneration, fibrous replacement, cicatricial contracture, cartilaginous metaplasia, and calcification after a short period of time following implantation (from 7 to 138 days).

The very good results obtained by Senning (1967) with fascia lata replacement of the aortic valve in humans over a period of six years contrast with results obtained in dogs. The basis of this discrepancy should necessarily be related to species variation, and it demonstrates once again that findings in animals should not be transposed directly to humans.

A few conclusions can be drawn from the extensive experimental and clinical work performed since the beginning of this century.

The matrix or intercellular substance is believed to be produced and maintained by the activity of the living cells or in association with them. Hence the necessity to transplant a living and immunologically acceptable tissue with metabolically active cells capable of 'servicing' the matrix.

The fibroblast represents the essential or parenchymal cell of fascia and it is the only one to be 
found in this tissue. In this respect fascia resembles cartilage in having a single essential cell type.

It seems probable that the transplanted cells continue to live after transfer for their normal lifespan, which is not known in most instances.

The fascia cells in the graft not only survive but divide at least once, so that the total cellular population of autogenous fascia grafts is about doubled (Peer, 1955).

When the fascia cells fail to survive, the fate of the collagenous fibres is not definitely known. If the graft is in contact with dissimilar tissue (not fascia) the fibres may disappear. When, however, it is in contact with similar tissue, it is possible for the fascia to be replaced by creeping substitution, as occurs in dead bone grafts which are in contact with living bone.

Cells which survive transplantation are, as a general rule, strictly true-breeding in their mitotic lineage and so retain their distinctive properties whether the transplantation is orthotopic or heterotopic (Woodruff, 1960).

In transplants of more complex structure, populated by cells of various kinds, some of which survive transplantation while others do not, the structure of the transplanted tissue is permanently altered. Both fascia and cartilage retain their structure unaltered after transplantation because they are unicellular tissues.

Since intercellular substances are usually interposed between capillaries and the cells which they nourish, all, regardless of their apparent density, must permit diffusion of substances from capillaries to cells and vice versa. This takes place even more easily when the transplanted tissue lies in the blood stream and is penetrated by the nourishing fluid under pressure, as happens in heart valve replacement.

\section{CONCLUSIONS}

Fascia presents qualities which make it a useful tissue for transplantation provided it is used as a living transplant. In this respect we shall define a viable transplant as one which is capable of surviving in a suitable environment. There are specific conditions necessary for survival of an autotransplant. The tissue transplanted should be healthy and free from infection. Adequate nutrition should be assured from the beginning, knowing that with free transplants the metabolic exchanges depend initially on the diffusion of fluid to and from the surrounding tissues. Mechanical stimulation is a prerequisite for maintenance of functional structure and morphological integrity of the transplanted tissue. The suitability of particular environments or 'soils', to use Paget's analogy, for free transplantation is very well illustrated in the case of fascial grafts for heart valve replacement, because the blood is an ideal culture medium for autogenous cells.

The advantages of fascia lata grafts over prosthetic devices are obvious. They have a central $\overrightarrow{0}$ opening, larger than in any known prosthesis they are atraumatic to the blood cells and are freew of thromboembolic complications without the use $=$ of anticoagulants. The geometry of the graft valvex is very close to the functional design of a normaler heart valve, and, being a three-cusp mechanism, its useful opening is equal to the surface area of its annulus. There is very little space-occupying? structure lying in the ventricular cavity. Thepliability and thinness of the fascia ensures a fasto closing and opening mechanism even at very rapide heart rates.

A homo- or heterograft attached to the inside of a supporting frame reduces the useful opening 0 of the graft. On the other hand, the fascial graft,. being attached outside the metal support, provides a larger central opening. In addition, the thickness of the wall of aortic homo- or heterografts is greater than that of a fascial strip.

It is certainly easier to build a fascial graft than $\frac{\mathbb{8}}{8}$ to attach and support a heterograft. Fascia lata $\overrightarrow{0}$ grafts can always be made perfectly competent, 3 being tailored individually to match the support ing frame. Aortic homo- and heterografts have unequal cusps, and the size of the sinuses of Valsalva differs slightly from valve to valve. Thiso gives rise to difficulties in ensuring a perfectly competent valve, as has been demonstrated in the pulse duplicator (Ionescu and Deac, personal. data). Testing of the frame-mounted aortic homo-o or heterografts is a necessity, while a fascia lata graft, if properly prepared, does not need to be윽 tested before implantation.

Fascia is a relatively non-vascular tissue and is well nourished by penetration if transplanted as N a heart valve replacement. Being a thin tissue it is unlikely to undergo central necrosis when used as a free transplant.

This technique of preparing supported valve? grafts presents several advantages. Using $x \circ$ cylinder of fascia, there is increased strength com- $\overline{\mathbb{\Phi}}$ pared with three separate leaflets. The construc-? tion of a perfect three-cusp valve with equal 0 leaflets is facilitated, and a good coaptation on $\frac{\vec{\Phi}}{\mathbb{D}}$ a large surface area is ensured.

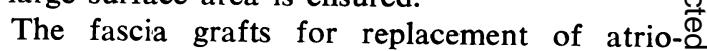
ventricular valves are built in such a way as to stay closed when in a resting position. This ensures 
a rapid closure of the valve even without the mechanism provided by the sinuses of Valsalva. The large Dacron skirt of the frame provides a flexible union between the rigid titanium ring and the continuously moving atrio-ventricular valve annulus.

The immediate results obtained with our patients are very good, but the follow-up period is too short to draw any conclusion concerning the long-term fate of autologous fascia lata valve grafts. However, Senning's (1967) good results with fascial grafts for aortic valve replacement demonstrate that fascia lata remains viable and well preserved years after transplantation. Our clinical results with mitral, aortic, and tricuspid valve replacement using autologous fascia lata valves mounted on to support frames showed a perfect haemodynamic function, absence of thromboembolic phenomena without anticoagulant treatment, and simplicity in the preparation and implantation of these valves. We consider that fascia lata valves could ultimately be superior to homoand heterografts for heart valve replacement because they are made of autologous, living tissue, which maintains its structure unchanged after transplantation. The fascia matrix is 'serviced' by living fibroblasts and, being under continuous mechanical stimulation, it retains its functional properties.

We wish to thank Professor Mario Ursini, Director of the Cardiovascular Surgical Center, Hospital for Sick Children, Naples, for allowing us to include four of his patients in this study. We thank Miss Berryl Walsh and the Department of Photography for the illustrations.

\section{REFERENCES}

Angell, W. W., Stinson, E. B., Iben, A. B., and Shumway, N. E. (1968). Multiple valve replacement with the fresh aortic homograft. J. thorac. cardiovasc. Surg., 56, 323.

Barratt-Boyes, B. G. (1964). Homograft aortic valve replacement in aortic incompetence and stenosis. Thorax, 19, 131.

Binet, J. P., Duran, C. G., Carpentier, A., and Langlois, J. (1965). Heterologous aortic valve transplantation. Lancet, 2, 1275.

Brock, Lord (1968). Long-term degenerative changes in aortic segment homografts, with particular reference to calcification. Thorax, 23, 249.

Bunnell, S. (1928). Fascial graft for dislocation of acromioclavicular joint. Surg. Gynec. Obstet., 46, 563.

Carpentier, A., Blondeau, P., Laurens, P., Mancel, P., Laurent, D., and Dubost, Ch. (1968). Remplacement des valvules mitrales et tricuspides par des hétérogreffes. Ann. Chir. thorac. Cardiovasc., $7,33$.

Chandy, J. (1946). The fate of preserved heterogeneous grafts of fascia when transplanted into living human tissues. Surg. Gynec. obstet., 83, 145.

Clark. W. E. Le Gros (1952). The Tissues of the Body, 3rd ed., p. 42. Clarendon Press, Oxford.

Cowdry, E. V. (1950). A Textbook of Histology, 4th ed. Iea and Febiger, Philadelphia.

Duran, C. G., Manley, G., and Gunning, A. J. (1965). The behaviour of homotransplanted aortic valves in the dog. Brit. J. Surg., $52,549$.
Flege, J. B., Jr., Rossi, N. P., Auer, J. E., and Ehrenhaft, J. L. (1967). Technique of mitral valve replacement with autologous fascia lata. J. thorac. cardiovasc. Surg., 54, 222.

Foshee, J. C. (1943). Fascia lata regeneration; preliminary repotr. Surgery, 14, 554.

(1947). Fascia lata regeneration. Final report. Ibid., 21, 819.

Gallie, W. E. (1948). Fascial grafts. In British Surgical Practice ed. Carling, E. Rock, and Ross, J. Paterson, Vol. 4, p. 70 Butterworth, London.

and LeMesurier, A. B. (1921). The use of living sutures in operative surgery. Canad. med. Ass. J., 11, 504.

- (1922). A clinical and experimental study of the free transplantation of fascia and tendon. J. Bone Jt Surg., 4, 600. - (1924). The transplantation of the fibrous tissues in the repair of anatomical defects. Brit. J. Surg., 12, 289. (1948). Recurring dislocation of the shoulder. J. Bone Jt Surg., 30B, 9.

Gibson, T. (1968). Cartilage transplantation. In Human Transplantation. By Rapaport, F. T., and Dausset, J., pp. 323-331. Grune and Stratton, New York and London.

and Davis, W. B. (1960). A bank of living homograft cartilage: a preliminary report. In Transactions of the International Society of Plastic Surgeorts, Second Congress, London, 1959, p. 452 Livingstone, Edinburgh and London.

- and Curran, R. C. (1958). The long-term survival of cartilage homografts in man. Brit. J. plast. Surg., 11, 177.

Gilbert, J. W., Jr., Mansour, K., Sanders, S., and Gravanis, M. B. (1968). Experimental reconstruction of the tricuspid valve with autologous fascia lata. Arch. Surg., 97, 149.

Hartig, F. (1966). Utberlegungen zur funktionellen Struktur der Fascien. Zbl. Vet.-Med. (Reihe A), 13, 85.

Hudson, R. E. B. (1966). Pathology of the human aortic valve homograft. Brit. Heart J., 28, 291.

Ionescu, M. I., and Ross, D. N. (1969). Heart-valve replacement with autologous fascia lata. Lancet, 2, 335

(1970) Holden, M., Hargreaves, M. D., and Wooler, G. H. Thorax (accepted for publication).

Wooler, G. H., Deac, R., and Ray, D. (1970). Replacement of heart valves with autologous fascia lata. Surgical technique. Brit. J. Surg. (accepted for publication).

- Wooler, G. H., Smith, D. R., and Grimshaw, V. A. (1967), Mitral valve replacement with aortic heterografts in humans. Thorax, 22, 305.

_- Whitaker, W., Smith, D. R., Taylor, S. H., and Hargreaves, M. D. (1968). Heart valve replacement with reinforced aortic heterografts. J. thorac. cardiovasc. Surg., 56, 333.

Kirschner, M. (1909). Ueber freie Sehnen- und Fascientransplantation. Beitr. klin. Chir., 65, 472.

- (1910). Die praktischen Ergebnisse der freien Fascien-Transplantation. Arch. klin. Chir., 92, 888.

Leopold, G. (1881). Experimentelle Untersuchungen über die Aetiologie der Geschwülste. Virchows Arch. path. Anat., 85, 283.

Lewis, D. (1917). Fascia and fat transplantations. Surg. Gynec. Obstet., 24, 127.

Lower, R. R., Pillsbury, R. C., Angell, W. W., and Kosek, J. C. (1966). Homograft heart valves. Circulation, 33, Suppl. 1, p. 135.

McArthur, L. L. (1901). Autoplastic sutures in hernia, and other diastases-preliminary report. J. Amer. med. Ass., 37, 1162. (1904). Autoplastic sutures in hernia and other diastases. Final report. Ibid., 43, 1039.

- (1913). Transplantation of tissues. Int. Clin., 1, 23rd series. p. 146.

Murphy, J. B. (1904). Ankylosis. Arthroplasty-clinical and experimental. Trans. Amer. surg. Ass., 22, 315.

Neuhof, H. (1923). The Transplantation of Tissues, p. 95. Appleton, New York.

O'Brien, M. F. (1967). Heterograft aortic valves for human use Valve bank, techniques of measurement, and implantation. $J$. thorac. cardiovasc. Surg., 53, 392.

Peer, L. A. (1955). Transplantation of Tissues, Vol. 1. Williams and Wilkins, Baltimore.

(1958). Sex chromatin study to determine the survival of cartilage homografts. Transplant. Bull., 5, 404.

Pullinger, B. D., and Pirie, A. (1942). Chronic inflammation due to implanted collagen. J. Path. Bact., 54, 341.

Ross, D. N. (1962). Homograft replacement of the aortic valve. Lancet, 2, 487.

(1967a). Homograft replacement of the aortic valve. Technique. Brit. J. Surg., 54, 165. 
(1967b). Replacement of aortic and mitral valves with a pulmonary autograft. Lancet, 2, 956.

Schwarz, E. (1922). Utber die anatomischen Vorgänge bei der Sehnenregeneration und dem plastischen Ersatz von Sehnendefekten durch Sehne, Fascie und Bindegewebe; eine experimentelle Studie. Dtsch. Z. Chir., 173, 301.

Senning, A. (1967). Fascia lata replacement of aortic valves. $J$. thorac. cardiovasc. Surg., 54, 465.

Shaw, H. A. (1915). Fascial transplantation with report of an unusual case. Northw. Med. (Seattle), 7, 388.

Smith, J. C. (1967). The pathology of human aortic valve homografts. Thorax, 22, 114.

Stearns, M. L. (1940). Studies on the development of connective tissue in transparent chambers in the rabbit's ear. Amer. $J$. Anat., 67, 55.

Viering, W. (1891). Experimentalle Untersuchungen über die Regeneration des Sehnengewebes. Virchows Arch. path Anat., 125, 252.

Wierzejewski, I. (1916). Die freie Faszienüberpflanzung. Münchener med. Wschr., 63, 875 .

Woodruff, M. F. A. (1960). The Transplantation of Tissues and Organs. Thomas, Springfield, Illinois.

\section{ADDENDUM}

Since this article was completed a further 75 patients have had heart valves replaced with autologous fascia lata grafts, bringing the total number to 151 .
In 62 patients the mitral valve was replaced, in 49 the aortic, in 4 the tricuspid, in 24 the mitral and aortic valves, in 6 the mitral and tricuspid valves, and 6 patients had mitral, aortic and tricuspid valve replacement. Twenty-eight patients died during the hospital stay $(18.5 \%$ hospital mortality).

As late complications 3 patients developed subacute bacterial endocarditis a short time after surgery, 4 have a diastolic aortic murmur, and 4 a systolic mitral murmur. These murmurs do not have haemodynamic implications so far, the patients being in a very good condition. Concerning the systolic murmur in mitral valve replacement we suspect that this murmur is produced by the fascia lata graft not being positioned high enough into the left atrium and obstructing partially the outflow tract of the left ventricle. This technical error should be seen and corrected at the time of surgery. The remaining patients are doing extremely well with a follow-up since April 1969. 